\title{
Grand Challenges in Chemical Treatment of Hazardous Pollutants
}

\author{
Varsha Srivastava * \\ Research Unit of Sustainable Chemistry, Faculty of Technology, University of Oulu, Oulu, Finland
}

Keywords: chemical treatment, electrochemical treatment, coagulation, precipitaion, flocculalion, emerging pollutants, heavy metal

\section{INTRODUCTION}

The tremendous growth in industrialization and urbanization has resulted in generation of large amount of wastewater as well as hazardous waste (Chai et al., 2021; Titchou et al., 2021). Heterogenous solid waste usually ends up in landfills which undergoes various physicochemical change (Xiong et al., 2019; Patel et al., 2021)The nature and composition of hazardous waste varies depending on the source materials. Leachate from landfill sites has the potential to affect the water quality if it further enters into water streams via rainwater/stormwater (Bishop et al., 1986; Gautam et al., 2019). Accumulation of hazardous pollutants result in soil, water and air pollution (Quesada et al., 2019; Alemany et al., 2021; Dionne and Walker, 2021; Nikolaeva et al., 2021; Yadav et al., 2021; Łyszczarz et al., 2021).

Heavy metals are widely used in different industries and due to their inefficient removal, they can directly or indirectly gain entry into water bodies. Metals are non-biodegradable and can easily accumulate in the environment (Gholizadeh and Hu, 2021; Xu et al., 2021). Different industries like textile, cosmetics, tannery, food and beverages release toxic bio-recalcitrant hazardous pollutants in the environment (Choina et al., 2013; Muszyński et al., 2019; Quesada et al., 2019; Keskin et al., 2021). The presence of both organic and inorganic pollutants in water bodies can harmfully affect the aquatic environment. Additionally, highly acidic or alkaline wastewater can also pose detrimental effects on aquatic environment.

Further, various organic pollutants like pharmaceuticals, EDCs, refractory organic and dyes can generate more toxic species due to degradation or interaction with other available pollutant species (Tijani et al., 2013). Sometimes, degraded byproducts are even more toxic in comparison to their parent compound (Yin et al., 2017). The presence of emerging contaminants (ECs) in the environment is of great concern due to their harmful impacts on one hand and great challenges in existing water treatment technologies in terms of their removal efficiency on the other hand (Ahmed et al., 2021; Zamri et al., 2021).

Consumption of polluted water can result in a great threat to living beings hence the wastewater needs to be properly treated before being discharged into the water bodies (Gitis and Hankins, 2018; Hussein and Jasim, 2021).

It is noteworthy that due to water scarcity and environmental pollution by emission of pollutants, there is a continual rising global concern regarding the treatment of wastewater in order to make it available for reuse (Hussein and Jasim, 2021; Patel et al., 2021). Due to inefficient traditional treatment technologies, varieties of pollutants reach into the environment which directly and/or indirectly affects flora and fauna. Removal of lower concentrations of pollutants is more challenging and varied concentrations of emerging pollutants can be detected in the municipal sludge and effluents of municipal wastewater treatment plants.

Hazardous waste and wastewater can be treated by physical, chemical, thermal, biological as well as physico-chemical methods. Conventional technologies like physico-chemical and biological treatment methods are mainly used for the treatment of wastewater and hazardous solid waste. 
However, the efficient operation of these systems is energyintensive and requires substantial operative and maintenance costs (Patel et al., 2021). The most promising approach for treatment of wastewater and hazardous solid waste requires recovery of possible resources, reduction of waste/wastewater and efficient removal of toxic pollutants (Ahmed et al., 2021). Existing wastewater treatment plants (WWTPs) technologies are unable to eliminate ECs hence low concentrations of these pollutants are detected in effluents.

Generally, the utilization of a single method for treating wastewater is not sufficient enough for ideal treatment. This issue can be handled by combining different processes following one after the other (Du et al., 2021; Huang et al., 2021; Hussein and Jasim, 2021). In recent years, hybrid systems, involving both conventional as well as advanced treatment processes, have received greater attention due to their enhanced efficiency in the removal of hazardous pollutants (Saúco et al., 2021; Kim et al., 2022). During the treatment of hazardous solid waste and wastewater, resources can be efficiently recovered whereas the treated wastewater can be reused for various applications.

Chemical treatments have been widely used for variety of hazardous pollutants and are very effective for solid waste as well as liquid waste or wastewater (Azbar et al., 2004; Reddy et al., 2010; Bustos-Terrones et al., 2021). Chemical treatment can alter the toxic waste into nontoxic end-products and help in their safe disposal. It mainly includes precipitation, ion-exchange, neutralization, oxidation, coagulation, flocculation and electrochemical process (Ullah et al., 2020; Patel et al., 2021).

Chemical treatments can effectively work on low/high concentrations of hazardous pollutants. The selection of any chemical treatment process is highly dependent on the target pollutants and their environment. It needs to be selected either alone or with a combination of other techniques to obtain efficient treatment results in a cost-effective manner and environmentally friendly approach with a view to meet the guidelines of environmental legislation.

\section{Challenges in Chemical Treatment of Hazardous Pollutants}

Chemical treatment has been found very effective in cases of hazardous solid waste, liquid-waste and wastewater effluents, but it is always restricted due to high cost of chemicals and generation of secondary waste which further needs to be treated for safe disposal. Due to strict environmental legislation, hazardous waste must be treated with appropriate technology which helps in reduction and recovery of resources. Chemical treatment like chlorination is effective but it is associated with generation of disinfection by-products (DBPs) (Song et al., 2021). Another chemical treatment like ozonation is effective against numerous recalcitrant pollutants but this process is highly energy intensive (Ben Hamida et al., 2017; Ben Hamida et al., 2018). Low mineralization efficiency, selectivity towards pollutants and low solubility in water make this approach more expensive (Wang and Chen, 2020). Application of coagulants in conventional water treatment processes result in generation of significant amount of silt (Bouchareb et al., 2020).

Utilization of higher amount of chemicals for reducing and treating hazardous pollutants is not a worthy approach for a sustainable solution. Moreover, Fenton process is effective in degradation of organic pollutants, but it is associated with iron sludge generation and covers a narrow $\mathrm{pH}$ range (Azbar et al., 2004). Further treatment of secondary waste generated in Fenton process requires sustainable treatment. Catalyst based treatment is found to be very effective in treatment of emerging pollutants and a wide range of homogeneous and heterogeneous catalysts have been developed for this purpose (Hammouda et al., 2017; Minh et al., 2019). Due to lack of efficient catalyst recovery system, finer particles of catalyst may reach into the effluent streams or may end up in a solid sludge which can further pose harmful effects on the environment.

There is an increasing demand for development of efficient greener chemical treatment technologies in order to minimize the secondary waste and reduce the chemical consumption. More emphasis should be given to the green approach for synthesis of catalyst to reduce the toxicity of tailored catalysts (Yadav et al., 2021). Possibility to use greener technology using biobased materials, natural minerals for developing ion exchange material, coagulant or catalyst can make the process of chemical treatment safer and greener. Application of biobased chemicals for catalyst preparation can be effective in this sequence.

Further, the electrochemical method has gained popularity in recent few years as it does not require the use of chemical reagents like other chemical treatment methods as the oxidation of organic pollutants takes place over the electrode (Bouchareb et al., 2020). Electrocoagulation, Electro-Fenton process, Electro-catalytic ozonation, photoelectron-Fenton process, Electrochemical-persulfate oxidation processes have been found to be effective in the removal of various pollutants (Ltaïef et al., 2018; MartínezHuitle and Panizza, 2018; Qiao and Xiong, 2021). However, development of high-quality electrode is still a challenging task and sometimes it is highly selective for pollutant species and there is always a need to perform some pretreatment steps in order to get effective results from electrochemical treatment approach. Further, leaching of toxic chemicals from electrode surface can generate trace concentration of chemicals in the effluents. However, electrochemical method by using green materials for electrode preparation can be very effective in terms of reduction of secondary pollutants. The combination of photocatalytic treatment and electrochemical treatment provides an emerging strategy to remove organic pollutants from waste streams.

In recent years, application of variety of chemicals in treatment of trace concentrations of emerging pollutants has increased but the adverse effects by accumulation of these chemicals in the environment are not studied well yet (Gitis and Hankins, 2018). Chemical treatments are very effective in the removal of wide range of hazardous pollutants from solid and 
liquid waste. On the contrary, they are highly dependent on the characteristics of the hazardous pollutants and need to be selected accordingly. There is a growing need for advancement in the effective ion exchange materials, catalyst materials, coagulant, efficient electrode materials for electrochemical approach etc. for an efficient and sustainable chemical treatment approach to provide safer environment.

The purpose of Chemical treatment "Specialty section within Frontiers in Environmental Chemistry" is to provide the latest and high-quality research paper and review paper in the research area of chemical treatment for hazardous pollutants from solid waste, liquid waste and wastewater.

\section{REFERENCES}

Ahmed, S. F., Mofijur, M., Nuzhat, S., Chowdhury, A. T., Rafa, N., Uddin, M. A., et al. (2021). Recent Developments in Physical, Biological, Chemical, and Hybrid Treatment Techniques for Removing Emerging Contaminants from Wastewater. J. Hazard. Mater. 416, 125912. doi:10.1016/ j.jhazmat.2021.125912

Alemany, S., Crous-Bou, M., Vilor-Tejedor, N., Milà-Alomà, M., Suárez-Calvet, M., Salvadó, G., et al. (2021). Associations between Air Pollution and Biomarkers of Alzheimer's Disease in Cognitively Unimpaired Individuals. Environ. Int. 157, 106864. doi:10.1016/j.envint.2021.106864

Azbar, N., Yonar, T., and Kestioglu, K. (2004). Comparison of Various Advanced Oxidation Processes and Chemical Treatment Methods for COD and Color Removal from a Polyester and Acetate Fiber Dyeing Effluent. Chemosphere 55, 35-43. doi:10.1016/j.chemosphere.2003.10.046

Ben Hamida, S., Iftekhar, S., Ambat, I., Srivastava, V., Sillanpää, M., Amri, Z., et al. (2018). Dry and Wet Ozonation of Denim: Degradation Products, Reaction Mechanism, Toxicity and Cytotoxicity Assessment. Chemosphere 203, 514-520. doi:10.1016/j.chemosphere.2018.03.199

Ben Hamida, S., Srivastava, V., Sillanpää, M., Shestakova, M., Tang, W. Z., and Ladhari, N. (2017). Eco-friendly Bleaching of Indigo Dyed Garment by Advanced Oxidation Processes. J. Clean. Prod. 158, 134-142. doi:10.1016/ j.jclepro.2017.04.166

Bishop, P. L., Brown, T. M., and Shively, W. E. (1986). "Alkalinity Releases and the Leaching of Heavy Metals from Stabilized/Solidified Wastes," in Chemistry for Protection of the Environment 1985. Editors L. Pawlowski, G. Alaerts, and W. J. Lacy (Amsterdam, Netherlands: Elsevier), 217-233. doi:10.1016/s01661116(08)70942-7

Bouchareb, R., Derbal, K., Özay, Y., Bilici, Z., and Dizge, N. (2020). Combined Natural/chemical Coagulation and Membrane Filtration for wood Processing Wastewater Treatment. J. Water Process. Eng. 37, 101521. doi:10.1016/ j.jwpe.2020.101521

Bustos-Terrones, Y. A., Hermosillo-Nevárez, J. J., Ramírez-Pereda, B., Vaca, M., Rangel-Peraza, J. G., Bustos-Terrones, V., et al. (2021). Removal of BB9 Textile Dye by Biological, Physical, Chemical, and Electrochemical Treatments. J. Taiwan Inst. Chem. Eng. 121, 29-37. doi:10.1016/ j.jtice.2021.03.041

Chai, W. S., Cheun, J. Y., Kumar, P. S., Mubashir, M., Majeed, Z., Banat, F., et al. (2021). A Review on Conventional and Novel Materials towards Heavy Metal Adsorption in Wastewater Treatment Application. J. Clean. Prod. 296, 126589. doi:10.1016/j.jclepro.2021.126589

Choina, J., Kosslick, H., Fischer, C., Flechsig, G.-U., Frunza, L., and Schulz, A. (2013). Photocatalytic Decomposition of Pharmaceutical Ibuprofen Pollutions in Water over Titania Catalyst. Appl. Catal. B: Environ. 129, 589-598. doi:10.1016/j.apcatb.2012.09.053

Dionne, J., and Walker, T. R. (2021). Air Pollution Impacts from a Pulp and Paper Mill Facility Located in Adjacent Communities, Edmundston, New Brunswick, Canada and Madawaska, Maine, United States. Environ. Challenges 5, 100245. doi:10.1016/j.envc.2021.100245

Du, Z., Ji, M., and Li, R. (2021). Enhanced Membrane Fouling Control and Trace Organic Compounds Removal during Microfiltration by Coupling Coagulation

\section{AUTHOR CONTRIBUTIONS}

The author confirms being the sole contributor of this work and has approved it for publication.

\section{ACKNOWLEDGMENTS}

I would like to acknowledge Dr. Yati A.P. Srivastava, for her very helpful contribution and constructive comments. Financial support from the Academy of Finland (decision number 346537) is gratefully acknowledged.

and Adsorption in an Electric Field. Sci. Total Environ. 795, 148830 doi:10.1016/j.scitotenv.2021.148830

Gautam, P., Kumar, S., and Lokhandwala, S. (2019). Advanced Oxidation Processes for Treatment of Leachate from Hazardous Waste Landfill: A Critical Review. J. Clean. Prod. 237, 117639. doi:10.1016/j.jclepro.2019.117639

Gholizadeh, M., and Hu, X. (2021). Removal of Heavy Metals from Soil with Biochar Composite: A Critical Review of the Mechanism. J. Environ. Chem. Eng. 9, 105830. doi:10.1016/j.jece.2021.105830

Gitis, V., and Hankins, N. (2018). Water Treatment Chemicals: Trends and Challenges. J. Water Process Eng. 25, 34-38. doi:10.1016/j.jwpe.2018.06.003

Hammouda, S. B., Zhao, F., Safaei, Z., Srivastava, V., Lakshmi Ramasamy, D., Iftekhar, S., et al. (2017). Degradation and Mineralization of Phenol in Aqueous Medium by Heterogeneous Monopersulfate Activation on Nanostructured Cobalt Based-Perovskite Catalysts $\mathrm{ACoO} 3(\mathrm{~A}=\mathrm{La}, \mathrm{Ba}, \mathrm{Sr}$ and $\mathrm{Ce}$ ): Characterization, Kinetics and Mechanism Study. Appl. Catal. B: Environ. 215, 60-73. doi:10.1016/j.apcatb.2017.05.051

Huang, H., Yang, C., He, C., Hu, X., Hu, Z., and Wang, W. (2021). Combining Biofilm and Membrane Flocculation to Enhance Simultaneous Nutrients Removal and Membrane Fouling Reduction. Sci. Total Environ. 796, 148922. doi:10.1016/j.scitotenv.2021.148922

Hussein, T. K., and Jasim, N. A. (2021). A Comparison Study between Chemical Coagulation and Electro-Coagulation Processes for the Treatment of Wastewater Containing Reactive Blue Dye. Mater. Today Proc. 42, 1946-1950. doi:10.1016/j.matpr.2020.12.240

Keskin, B., Ersahin, M. E., Ozgun, H., and Koyuncu, I. (2021). Pilot and Full-Scale Applications of Membrane Processes for Textile Wastewater Treatment: A Critical Review. J. Water Process Eng. 42, 102172. doi:10.1016/ j.jwpe.2021.102172

Kim, S., Nam, S.-N., Jang, A., Jang, M., Park, C. M., Son, A., et al. (2022). Review of Adsorption-Membrane Hybrid Systems for Water and Wastewater Treatment. Chemosphere 286, 131916. doi:10.1016/j.chemosphere.2021.131916

Ltaïef, A. H., Sabatino, S., Proietto, F., Ammar, S., Gadri, A., Galia, A., et al. (2018). Electrochemical Treatment of Aqueous Solutions of Organic Pollutants by Electro-Fenton with Natural Heterogeneous Catalysts under Pressure Using Ti/ IrO2-Ta2O5 or BDD Anodes. Chemosphere 202, 111-118. doi:10.1016/ j.chemosphere.2018.03.061

Łyszczarz, S., Lasota, J., Staszel, K., and Błońska, E. (2021). Effect of forest and Agricultural Land Use on the Accumulation of Polycyclic Aromatic Hydrocarbons in Relation to Soil Properties and Possible Pollution Sources. For. Ecol. Manage. 490, 119105. doi:10.1016/j.foreco.2021.119105

Martínez-Huitle, C. A., and Panizza, M. (2018). Electrochemical Oxidation of Organic Pollutants for Wastewater Treatment. Curr. Opin. Electrochemistry 11, 62-71. doi:10.1016/j.coelec.2018.07.010

Minh, T. D., Ncibi, M. C., Srivastava, V., Thangaraj, S. K., Jänis, J., and Sillanpää, M. (2019). Gingerbread Ingredient-Derived Carbons-Assembled CNT Foam for the Efficient Peroxymonosulfate-Mediated Degradation of Emerging Pharmaceutical Contaminants. Appl. Catal. B: Environ. 244, 367-384. doi:10.1016/j.apcatb.2018.11.064

Muszyński, A., Marcinowski, P., Maksymiec, J., Beskowska, K., Kalwarczyk, E., and Bogacki, J. (2019). Cosmetic Wastewater Treatment with Combined light/Fe0/ H2O2 Process Coupled with Activated Sludge. J. Hazard. Mater. 378, 120732. doi:10.1016/j.jhazmat.2019.06.009 
Nikolaeva, O., Karpukhin, M., Streletskii, R., Rozanova, M., Chistova, O., and Panina, N. (2021). Linking Pollution of Roadside Soils and Ecotoxicological Responses of Five Higher Plants. Ecotoxicology Environ. Saf. 208, 111586. doi:10.1016/j.ecoenv.2020.111586

Patel, A., Arkatkar, A., Singh, S., Rabbani, A., Solorza Medina, J. D., Ong, E. S., et al. (2021). Physico-chemical and Biological Treatment Strategies for Converting Municipal Wastewater and its Residue to Resources. Chemosphere 282, 130881. doi:10.1016/j.chemosphere.2021.130881

Qiao, J., and Xiong, Y. (2021). Electrochemical Oxidation Technology: A Review of its Application in High-Efficiency Treatment of Wastewater Containing Persistent Organic Pollutants. J. Water Process Eng. 44, 102308. doi:10.1016/ j.jwpe.2021.102308

Quesada, H. B., Baptista, A. T. A., Cusioli, L. F., Seibert, D., de Oliveira Bezerra, C., and Bergamasco, R. (2019). Surface Water Pollution by Pharmaceuticals and an Alternative of Removal by Low-Cost Adsorbents: A Review. Chemosphere 222, 766-780. doi:10.1016/j.chemosphere.2019.02.009

Reddy, D. A., Khandelwal, S. K., Muthiah, R., Shanmugamani, A. G., Paul, B., Rao, S. V. S., et al. (2010). Conditioning of Sludge Produced through Chemical Treatment of Radioactive Liquid Waste - Operating Experiences. Ann. Nucl. Energ. 37, 934-941. doi:10.1016/j.anucene.2010.03.014

Saúco, C., Cano, R., Marín, D., Lara, E., Rogalla, F., and Arbib, Z. (2021). Hybrid Wastewater Treatment System Based in a Combination of High Rate Algae Pond and Vertical Constructed Wetland System at Large Scale. J. Water Process Eng. 43, 102311. doi:10.1016/j.jwpe.2021.102311

Song, Z.-M., Yang, L.-L., Lu, Y., Wang, C., Liang, J.-K., Du, Y., et al. (2021). Characterization of the Transformation of Natural Organic Matter and Disinfection Byproducts after Chlorination, Ultraviolet Irradiation and Ultraviolet Irradiation/chlorination Treatment. Chem. Eng. J. 426, 131916. doi:10.1016/j.cej.2021.131916

Tijani, J. O., Fatoba, O. O., and Petrik, L. F. (2013). A Review of Pharmaceuticals and Endocrine-Disrupting Compounds: Sources, Effects, Removal, and Detections. Water Air Soil Pollut. 224, 1770. doi:10.1007/s11270-013-1770-3

Titchou, F. E., Zazou, H., Afanga, H., El Gaayda, J., Ait Akbour, R., Nidheesh, P. V., et al. (2021). Removal of Organic Pollutants from Wastewater by Advanced Oxidation Processes and its Combination with Membrane Processes. Chem. Eng. Process. - Process Intensification 169, 108631. doi:10.1016/ j.cep. 2021.108631

Ullah, A., Hussain, S., Wasim, A., and Jahanzaib, M. (2020). Development of a Decision Support System for the Selection of Wastewater Treatment
Technologies. Sci. Total Environ. 731, 139158. doi:10.1016/ j.scitotenv.2020.139158

Wang, J., and Chen, H. (2020). Catalytic Ozonation for Water and Wastewater Treatment: Recent Advances and Perspective. Sci. Total Environ. 704, 135249. doi:10.1016/j.scitotenv.2019.135249

Xiong, X., Liu, X., Yu, I. K. M., Wang, L., Zhou, J., Sun, X., et al. (2019). Potentially Toxic Elements in Solid Waste Streams: Fate and Management Approaches. Environ. Pollut. 253, 680-707. doi:10.1016/j.envpol.2019.07.012

Xu, S.-J., Shen, Q., Luo, L.-H., Tong, Y.-H., Wu, Y.-Z., Xu, Z.-L., et al. (2021). Surfactants Attached Thin Film Composite (TFC) Nanofiltration (NF) Membrane via Intermolecular Interaction for Heavy Metals Removal. J. Memb. Sci. 642, 119930. doi:10.1016/j.memsci.2021.119930

Yadav, N., Garg, V. K., Chhillar, A. K., and Rana, J. S. (2021). Detection and Remediation of Pollutants to Maintain Ecosustainability Employing Nanotechnology: A Review. Chemosphere 280, 130792. doi:10.1016/ j.chemosphere.2021.130792

Yin, L., Wang, B., Yuan, H., Deng, S., Huang, J., Wang, Y., et al. (2017). Pay Special Attention to the Transformation Products of PPCPs in Environment. Emerging Contaminants 3, 69-75. doi:10.1016/j.emcon.2017.04.001

Zamri, M. F. M. A., Bahru, R., Suja', F., Shamsuddin, A. H., Pramanik, S. K., and Fattah, I. M. R. (2021). Treatment Strategies for Enhancing the Removal of Endocrine-Disrupting Chemicals in Water and Wastewater Systems. J. Water Process Eng. 41, 102017. doi:10.1016/j.jwpe.2021.102017

Conflict of Interest: The author declares that the research was conducted in the absence of any commercial or financial relationships that could be construed as a potential conflict of interest.

Publisher's Note: All claims expressed in this article are solely those of the authors and do not necessarily represent those of their affiliated organizations, or those of the publisher, the editors and the reviewers. Any product that may be evaluated in this article, or claim that may be made by its manufacturer, is not guaranteed or endorsed by the publisher.

Copyright (c) 2021 Srivastava. This is an open-access article distributed under the terms of the Creative Commons Attribution License (CC BY). The use, distribution or reproduction in other forums is permitted, provided the original author(s) and the copyright owner(s) are credited and that the original publication in this journal is cited, in accordance with accepted academic practice. No use, distribution or reproduction is permitted which does not comply with these terms. 